Regional environmental conditions determine tolerance to future warming of a marine macroalgae forests

Jana Verdura ${ }^{1}$, Sonia de Caralt ${ }^{1,2}$, Jorge Santamaria ${ }^{1}$, Alba Verges ${ }^{1}$, Luisa Mangialajo ${ }^{3}$, Ljiliana Ivesa ${ }^{4}$, Simone Farina ${ }^{5}$, Maria Elena Cefalí ${ }^{6}$, Simonetta Fraschetti ${ }^{7}$, Enric Ballesteros ${ }^{2}$, Emma Cebrian ${ }^{1}$

${ }^{1}$ GRMAR Institute of Aquatic Ecology, University of Girona, Girona, Catalonia, Spain

${ }^{2}$ Centre d'Estudis Avançats de Blanes, Consejo Superior de Investigaciones Cientificas, Blanes, Catalonia, Spain

${ }^{3}$ Université Nice Sophia Antipolis, EA 4228 ECOMERS, 06108 Nice Cedex 2, France

${ }^{4}$ Ruder Bo\$̣kovic Institute, Center for Marine Research, G. Paliaga 5, 52210 Rovinj, Croatia

${ }^{5}$ Fondazione IMC, Centro Marino Internazionale Onlus, Localitá Sa Mardini, IT-09170 Torre Grande, Oristano, Italy

${ }^{6}$ Estació d’Investigació Jaume Ferrer, Instituto Español de Oceanografía, Maó, Menorca, Spain

${ }^{7}$ Laboratory of Marine Biology, Università del Salento, CoNISMa, Lecce, Italy

Corresponding Author:

Emma Cebrian $^{1}$

E mail address: emma.cebrian@udg.edu 


\section{Regional environmental conditions determine tolerance to future warming of a marine macroalgae forests}

Jana Verdura ${ }^{1}$, Sonia de Caralt ${ }^{1,2}$, Jorge Santamaria ${ }^{1}$, Alba Verges $^{1}$, Luisa Mangialajo ${ }^{3}$, Ljiliana Ivesa ${ }^{4}$, Simone Farina ${ }^{5}$, Maria Elena Cefali ${ }^{6}$, Simonetta Fraschetti ${ }^{7}$, Enric Ballesteros ${ }^{2}$, Emma Cebrian ${ }^{1}$

${ }^{1}$ GRMAR Institute of Aquatic Ecology, University of Girona, Girona, Catalonia, Spain

${ }^{2}$ Centre d'Estudis Avançats de Blanes, Consejo Superior de Investigaciones Cientificas, Blanes, Catalonia, Spain

${ }^{3}$ Université Nice Sophia Antipolis, EA 4228 ECOMERS, 06108 Nice Cedex 2, France

${ }^{4}$ Ruder Bo\$\$kovic Institute, Center for Marine Research, G. Paliaga 5, 52210 Rovinj, Croatia

${ }^{5}$ Fondazione IMC, Centro Marino Internazionale Onlus, Localitá Sa Mardini, IT-09170 Torre Grande, Oristano, Italy

${ }^{6}$ Estació d'Investigació Jaume Ferrer, Instituto Español de Oceanografía, Maó, Menorca, Spain

${ }^{7}$ Laboratory of Marine Biology, Università del Salento, CoNISMa, Lecce, Italy

In the Mediterranean Sea, many species of Cystoseira, which are important habitat-forming species on shallow rocky bottoms, have gone missing from many coastal areas, impairing essential ecosystem services. Cystoseira crinita forests thrive in very shallow waters from sheltered environments and are currently regressing in several European shores. In the actual scenario of ocean warming it is essential to determine the vulnerability of these populations to thermal stress in order to design future conservation actions. Since the response of this macroalgae to thermal stress may be site-specific, here we compared the thermal tolerance of populations dwelling in the coldest and warmest areas of the Mediterranean Sea. We show that $C$. crinita populations from warmer areas (Eastern Mediterranean) had a temperature tolerance threshold $2^{\circ} \mathrm{C}$ higher than Northwestern Mediterranean populations. There is a strong correlation between the observed differential phenotypic responses and the local temperature regimes experienced by each population. This is the first evidence for the role of thermal history in shaping the thermotolerance responses marine habitat-forming macroalgae under contrasting temperature environments. 
(c) 2018 Verdura et al. This is an open access article distributed under the terms of the Creative Commons Attribution License: http://creativecommons.org/licenses/by/4.0/ (the "License"), which permits unrestricted use, distribution, reproduction and adaptation in any medium and for any purpose provided that it is properly attributed. For attribution, the original author(s), title, publication source (PeerJ Preprints) and either DOI or URL of the article must be cited. Notwithstanding the ProQuest Terms and Conditions, you may use this content in accordance with the terms of the License. 